\title{
MICROALBUMINURIA IN NON-PROTEINURIC DIABETIC PATIENTS AND ITS CORRELATION WITH DIABETIC RETINOPATHY AND NEUROPATHY- A CROSS-SECTIONAL STUDY IN A TERTIARY CARE HOSPITAL
}

\author{
Sujata Raychaudhuri ${ }^{1}$, Nimisha Sharma², Deepshikha Rana ${ }^{3}$
}

${ }^{1}$ Associate Professor, Department of Pathology, ESIC Medical College and Hospital, Faridabad.

${ }^{2}$ Assistant Professor, Department of Pathology, ESIC Medical College and Hospital, Faridabad.

${ }^{3}$ Tutor, Department of Pathology, ESIC Medical College and Hospital, Faridabad.

\section{ABSTRACT}

\section{BACKGROUND}

Diabetes is a stage of persistent hyperglycaemia due to absolute or relative deficiency of insulin. Microalbuminuria is often the first sign of renal dysfunction in diabetes. Microalbuminuria is defined as the urinary excretion of albumin of 20-200 $\mu \mathrm{g} / \mathrm{min}$. or 30-300 $\mathrm{mg} / 24$ hours with a negative dipstick test.

The aim of the study is to evaluate the frequency of MAU amongst studied population of diabetic patients of different age group, sex, duration and types of diabetes. The study was also used to establish relationship of MAU with serum cholesterol, serum creatinine, retinopathy and diabetic neuropathy.

\section{MATERIALS AND METHODS}

The study was conducted in BJMC, Civil Hospital, Ahmedabad over the period of two years on 91 admitted cases of diabetes lying in the age group of 15-75 years. The study was restricted to use of Micral II strips manufactured by the Boehringer Mannheim India Limited. It is based on the principle of immunologic detection of human albumin by means of soluble antibody-gold conjugate. First morning sample was used for the study. MAU is positive when there is colour change ranging from peach $(20-50 \mathrm{mg} / \mathrm{L})$ to light pink (50-100 mg/L) to dark pink (>100 mg/L), corresponding to increasing values of MAU.

\section{RESULTS}

In the present study conducted amongst 91 diabetic patients, $57 \%$ of the patients showed Micral positivity with male to female ratio of 2.25:1. Statistically significant correlation was seen between microalbuminuria and duration of diabetes, value of serum creatinine, serum cholesterol and serum protein respectively. Out of $36 \%$ patients with duration of diabetes $<2$ years, approximately one third tested positive for microalbuminuria. As the duration of diabetes advances from 10 years to more than 20 years, number of positive cases rises from $72 \%$ to $100 \%$. Of the 48 patients with evidence of diabetic retinopathy, $60 \%$ showed positive results for microalbuminuria.

\section{CONCLUSION}

We investigated microalbuminuria in diabetes patients to emphasise the need for routine screening and better control of risk factors preceding ESRD.

\section{KEYWORDS}

Diabetes, Microalbuminuria, Nephropathy, Micral.

HOW TO CITE THIS ARTICLE: Raychaudhuri S, Sharma N, Rana D. Microalbuminuria in non proteinuric diabetic patients and its correlation with diabetic retinopathy and neuropathy- A cross-sectional study in a tertiary care hospital. J. Evolution Med. Dent. Sci. 2017;6(63):4603-4608, DOI: 10.14260/Jemds/2017/996

\section{BACKGROUND}

Diabetes mellitus is the most common chronic metabolic disorder characterised by elevation of blood glucose concentration and caused by relative or absolute deficiency of insulin leading to disturbances of carbohydrate, fat, and protein metabolism. ${ }^{1}$ If left untreated this will lead to a state of metabolic chaos leading to long term complications involving the eyes, kidney, nerves and blood vessels. The risk of chronic complication increases with the duration of hyperglycaemia. ${ }^{2}$

Financial or Other, Competing Interest: None.

Submission 14-06-2017, Peer Review 25-07-2017,

Acceptance 01-08-2017, Published 07-08-2017.

Corresponding Author:

Dr. Nimisha Sharma,

\#3067, B4, Ridge View Apartments,

Vasant Kunj.

E-mail: nims427@gmail.com

DOI: $10.14260 /$ jemds $/ 2017 / 996$
It is estimated that more than 346 million people worldwide have diabetes mellitus. ${ }^{3}$ By the year 2030, it is predicted that diabetes will become the seventh leading cause of death in the world. The prevalence rate in India is higher than in other countries. The morbidity due to kidney disease could be very high due to large absolute number of individuals in our country. Asian Indians with NIDDM are more prone to diabetic kidney disease. ${ }^{4}$ These studies have proposed that Indians have a genetic tendency to develop diabetes. The studies done at the diabetic research centre have shown there is increasing prevalence of diabetes in the urban population. ${ }^{4}$ ESRD occurs in $30 \%$ of IDDM patients and accounts for $20 \%$ of deaths in patients $<40$ years. Another $2.5 \%$ of diabetics are estimated to have the disease without knowing its existence to them. Diabetes has become the single most common cause of end stage renal disease. About $20-40 \%$ of patients with type 2 diabetes develop evidence of nephropathy. ${ }^{5}$ 
Microalbuminuria (MAU) is the first identifiable sign of renal damage and cardiovascular complication. ${ }^{6}$ It refers to urine albumin excretion rate of $30-299 \mathrm{mg} /$ day or $20-300$ $\mathrm{mg} / \mathrm{L.}^{7}$ It predicts the development of diabetic nephropathy. The biggest advantage of detecting microalbuminuria is that prevention is achieved at this early stage. Early intervention with antihypertensive particularly ACE inhibitors, improved glycaemic control and low protein diet have shown to postpone the progression to overt nephropathy in these patients by $60 \%{ }^{4}$

Presence of microalbuminuria was similar in insulin treated and oral hypoglycaemic treated patients. Higher prevalence of MAU in Asian Indians with NIDDM as compared to the European patients has been noted. 4

In the present study, we tried to evaluate the frequency of MAU amongst studied population of diabetic patients of different age group, sex, duration and types of diabetes. The study was also used to establish relationship of MAU with serum cholesterol, serum creatinine, retinopathy and diabetic neuropathy.

\section{MATERIALS AND METHODS}

This descriptive study was conducted in BJMC, Civil Hospital, Ahmedabad over the period of two years. 100 patients who admitted with diabetes mellitus were evaluated for proteinuria by urine dipstick method. Sample size was selected as per convenience. 9 patients presented with frank proteinuria. 91 non-proteinuric patients (Nil or traces of urinary protein by dipstick Method) out of 100 evaluated constituted our sample size. Statistical analysis of result was done using ratio and proportions. Patients were lying in the age group of 15-75 years of which 54 were males and 37 were females. 66 patients were above 45 years of age. 45 cases had history of more than 5 years of diabetes.

\section{Inclusion Criterion}

1. IPD cases of diabetes.

2. All NIDDM cases and IDDM with more than 5 years' history.

3. Only freshly voided morning urine samples.

\section{Exclusion Criterion}

1. IDDM patients with less than 5 years' history of diabetes.

2. Patients with frank proteinuria on urine dipstick test.

The study was restricted to use of Micral II strips manufactured by the Boehringer Mannheim India Limited. It is an immunologic detection of human albumin by means of soluble antibody-gold conjugate. Excess conjugate is retained in a separation zone containing immobilised human albumin. Micral II test strips provide a screening test for microalbuminuria rather than providing a quantitative detection of microalbumin in urine. It helps to identify samples that require further quantitation.

\section{Sample Collection}

First morning sample was used for the study as it is easily available and is concentrated which allows for easy detection. The strips are stored at $2-8^{\circ} \mathrm{C}$ and are brought to room temperature before performing the test.

\section{Methodology}

100 urine samples were collected of which 91 cases tested nil or trace for protein by Ames dipstick. Only these 91 cases were included in the study-

1. The first morning sample was collected and test performed within two to three hours to prevent need for refrigeration and to minimise bacterial contamination.

2. The test strip is immersed in urine contained in the vessel, such that the urine level is between the two black marks on the strip. It is then drawn after 5 seconds and placed across the top of the urine vessel. The strip should not touch the sides of vessel during the entire procedure.

3. Compare the colour of the test pad with the colour scale on the test strip container. If the colour developed is uneven then the average colour is considered relevant.

- The colour is stable for another five minutes for comparison.

- The range of the colour and the level of microalbuminuria are indicated on the test strip container.

- Reaction colour lighter than the colour block corresponding to approx. $20 \mathrm{mg} / \mathrm{L}$ albumin indicates physiological urine albumin concentration.

- Screening result is positive when at least two of the three tested produce a colour corresponding to 20 $\mathrm{mg} / \mathrm{L}$ (Threshold value for microalbuminuria) or more.

\section{Inference}

MAU is negative when there is no colour change that is 'white' of the test strip. It corresponds to urine albumin concentration less the $20 \mathrm{mg} / \mathrm{L}$.

MAU is positive when there is colour change ranging from peach (20-50 mg/L) to light pink (50-100 mg/L) to dark pink ( $>100 \mathrm{mg} / \mathrm{L}$ ), corresponding to increasing values of MAU.

The data classifies intensity of microalbuminuria under four heads-

- Category A: 0-20 mg/L of microalbuminuria in urine.

- Category B: 20-50 mg/L of microalbuminuria in urine.

- Category C: $50-100 \mathrm{mg} / \mathrm{L}$ of microalbuminuria in urine.

- Category D: >100 mg/L of microalbuminuria in urine.

Micral positive is defined as $\mathrm{B}+\mathrm{C}+\mathrm{D}$, Micral negativity is defined as A.

A 5-mL sample of blood was drawn after overnight fasting of 12 hours to measure fasting blood sugar, serum cholesterol, and serum creatinine levels. Sample for postprandial blood sugar was taken two hours after meals. The data has been classified under different heads like age, sex, type and duration of diabetes, chief presenting complaints along with values of urine albumin, serum creatinine, serum cholesterol, fasting and postprandial blood sugar.

\section{Statistical Analysis}

The categorical variables are presented as proportions and continuous variables as mean. The difference in proportions were tested using Chi square test and the test of significance applied to test the difference between means is student $t$ test. Level of significance was set at $5 \%$. The statistical analysis 
was done using Epi info version 7. $\mathrm{P}$ value $<=0.05$ was considered significant.

\section{RESULTS}

In the present study, 100 IPD patients with Diabetes were evaluated for urinary albumin. 9 patients tested positive whereas 91 turned out to be negative for albumin in urine. These 91 patients formed our study group and were evaluated for microalbuminuria by Micral strip test. In the study conducted amongst these 91 diabetic patients, $58.2 \%$ of the patients showed Micral positivity. $62 \%$ of the females tested positive as against $55.6 \%$ male subjects. ( $\mathrm{p}=0.67 \%)$. On comparing type 1 versus type 2 diabetes, $61 \%$ of the type 2 cases tested positive as against $42 \%$ of the type 1 for MAU, indicating higher prevalence in NIDDM cases, however, this association was not found to be statistically significant $(\mathrm{p}=$ $0.25 \%$ ). No significant statistical association was found between microalbuminuria and nil or traces of urinary albumin in the patients studied ( $\mathrm{p}=0.63 \%) .47$ out of 91 patient showed evidence of diabetic retinopathy. Of these 47 patients, $66 \%$ showed positive results for microalbuminuria $(p=0.12)$. Of the 91 IPD patients evaluated, diabetic foot, tingling, numbness and MI were the chief clinical complaints. Statistically significant association was found between clinical complaints and secretion of microalbumin in urine in our study ( $\mathrm{p}=0.01 \%)$ (Table 1$)$.

\begin{tabular}{|c|c|c|c|c|c|}
\hline \multirow[t]{2}{*}{ Variables } & & \multicolumn{2}{|c|}{ Microalbuminuria } & \multirow[b]{2}{*}{ Total } & \multirow[b]{2}{*}{ P value } \\
\hline & & Positive & Negative & & \\
\hline \multirow[t]{2}{*}{ Total } & & 53 & 38 & 91 & \\
\hline & & $58.2 \%$ & $41.8 \%$ & $100.0 \%$ & \\
\hline \multirow[t]{4}{*}{ Sex } & Female & 23 & 14 & 37 & 0.67 \\
\hline & & $62.2 \%$ & $37.8 \%$ & $100.0 \%$ & \\
\hline & Male & 30 & 24 & 54 & \\
\hline & & $55.6 \%$ & $44.4 \%$ & $100.0 \%$ & \\
\hline \multirow[t]{4}{*}{ Diabetes type } & I & 6 & 8 & 14 & 0.25 \\
\hline & & $42.9 \%$ & $57.1 \%$ & $100.0 \%$ & \\
\hline & II & 47 & 30 & 77 & \\
\hline & & $61.0 \%$ & $39.0 \%$ & $100.0 \%$ & \\
\hline Urine albumin & NIL & 39 & 30 & 69 & 0.63 \\
\hline \multirow[t]{3}{*}{ (Uristix method) } & & $56.5 \%$ & $43.5 \%$ & $100.0 \%$ & \\
\hline & Traces & 14 & 8 & 22 & \\
\hline & & $63.6 \%$ & $36.4 \%$ & $100.0 \%$ & \\
\hline \multirow[t]{10}{*}{ Fundus } & BDR & 2 & 0 & 2 & 0.12 \\
\hline & & $100.0 \%$ & $0.0 \%$ & $100.0 \%$ & \\
\hline & Cataract & 2 & 4 & 6 & \\
\hline & & $33.3 \%$ & $66.7 \%$ & $100.0 \%$ & \\
\hline & Diabetic ret & 31 & 16 & 47 & \\
\hline & & $66.0 \%$ & $34.0 \%$ & $100.0 \%$ & \\
\hline & NAD & 16 & 18 & 34 & \\
\hline & & $47.1 \%$ & $52.9 \%$ & $100.0 \%$ & \\
\hline & PDR & 2 & 0 & 2 & \\
\hline & & $100.0 \%$ & $0.0 \%$ & $100.0 \%$ & \\
\hline \multirow[t]{18}{*}{ Complaints } & Burning Micturition & 0 & 4 & 4 & 0.01 \\
\hline & & $0.0 \%$ & $100.0 \%$ & $100.0 \%$ & \\
\hline & CV Stroke & 8 & 4 & 12 & \\
\hline & & $66.7 \%$ & $33.3 \%$ & $100.0 \%$ & \\
\hline & Diabetic Foot & 11 & 6 & 17 & \\
\hline & & $64.7 \%$ & $35.3 \%$ & $100.0 \%$ & \\
\hline & Dim. of. Vision & 6 & 0 & 6 & \\
\hline & & $100.0 \%$ & $0.0 \%$ & $100.0 \%$ & \\
\hline & Giddiness & 4 & 2 & 6 & \\
\hline & & $66.7 \%$ & $33.3 \%$ & $100.0 \%$ & \\
\hline & MI & 12 & 2 & 14 & \\
\hline & & $85.7 \%$ & $14.3 \%$ & $100.0 \%$ & \\
\hline & Numbness & 4 & 2 & 6 & \\
\hline & & $66.7 \%$ & $33.3 \%$ & $100.0 \%$ & \\
\hline & Polydipsia & 2 & 4 & 6 & \\
\hline & & $33.3 \%$ & $66.7 \%$ & $100.0 \%$ & \\
\hline & Polyuria & 2 & 8 & 10 & \\
\hline & & $20.0 \%$ & $80.0 \%$ & $100.0 \%$ & \\
\hline
\end{tabular}

The age of diabetic patients selected for study varied from 15 to 75 years, with peak incidence in the age group 45-55 years. Mean age of patients tested positive for microalbuminuria is 56.55 years ( $\mathrm{p}=0.07$ ) (Table 2).
Out of $36 \%$ patients with duration of diabetes $<2$ years, approximately one third tested positive for microalbuminuria. As the duration of diabetes advances from 10 years to more than 20 years, number of positive cases rises from $72 \%$ to $100 \%$. The present study shows increasing 
incidence of MAU after 7 years of diagnosis of diabetes whether IDDM or NIDDM. The incidence decreases after 20 years. Significant statistical correlation is found between microalbuminuria and duration of diabetes $(\mathrm{p}=0.01)$. (Table 2, 3)

On comparing the positivity of strip test with serum creatinine values, a positive correlation was seen in the rising serum levels of creatinine with the micro albumin excretion in urine. $50 \%, 60 \%, 70 \%$ and $100 \%$ positive micral results were seen in $<1.0,1.0-1.5,1.5-2.0$ and $>2.0$ sub-groups (Table $2,4)$. However, this association was found to be statistically significant ( $\mathrm{p}=0.01)$.

In present study, prevalence of microalbuminuria is $18 \%$, $61 \%, 61 \%$ and $66 \%$ amongst the patients with serum cholesterol 150, 150-200, 200-250 and $>250 \mathrm{mg} / \mathrm{dL}$ respectively $(\mathrm{p}=0.04)$. (Table 2,5$)$. Association between serum protein and microalbumin is statistically significant $(\mathrm{p}=0.01)$. (Table 2,6) $60.0 \%$ of diabetic patients having FBS > $120 \mathrm{mg} / \mathrm{dL}$ had microalbuminuria $(\mathrm{p}=0.91)$ whereas $80.6 \%$ of diabetic patients having PPBS $>250 \mathrm{mg} / \mathrm{dL}$ had microalbuminuria. $(\mathrm{p}=0.14)$.

\begin{tabular}{|c|c|c|c|c|c|}
\hline & $\begin{array}{c}\text { Micro- } \\
\text { Albuminuria }\end{array}$ & N & Mean & $\begin{array}{c}\text { Std. } \\
\text { Deviation }\end{array}$ & $\begin{array}{c}\text { P } \\
\text { value }\end{array}$ \\
\hline Age & Positive & 53 & 56.55 & 11.23 & 0.07 \\
\hline & Negative & 38 & 51.68 & 13.89 & \\
\hline $\begin{array}{c}\text { Duration } \\
\text { of DM }\end{array}$ & Positive & 53 & 8.92 & 7.45 & 0.01 \\
\hline & Negative & 38 & 5.03 & 5.41 & \\
\hline $\begin{array}{c}\text { Serum } \\
\text { Creatinine }\end{array}$ & Positive & 53 & 1.11 & 0.52 & 0.01 \\
\hline $\begin{array}{c}\text { Serum } \\
\text { Choles- } \\
\text { terol }\end{array}$ & Pegative & 38 & 0.86 & 0.33 & \\
\hline & Pegative & 38 & 186.78 & 32.32 & 0.04 \\
\hline $\begin{array}{c}\text { Serum } \\
\text { Protein }\end{array}$ & Positive & 53 & 6.46 & 0.70 & 0.01 \\
\hline & Negative & 38 & 6.04 & 0.68 & \\
\hline FBS & Positive & 53 & 149.88 & 51.78 & 0.91 \\
\hline & Negative & 38 & 148.57 & 59.59 & \\
\hline PPBS & Positive & 53 & 201.77 & 62.85 & 0.14 \\
\hline & Negative & 38 & 225.36 & 87.33 & \\
\hline Table 2. Correlation of & MAU with Continuous Variables \\
\hline
\end{tabular}

Table 2. Correlation of MAU with Continuous Variables

\begin{tabular}{|c|c|c|c|c|c|c|}
\hline $\begin{array}{c}\text { Duration } \\
\text { (Years) }\end{array}$ & $\begin{array}{c}\text { A } \\
\text { (\%) }\end{array}$ & $\begin{array}{c}\text { B } \\
\text { (\%) }\end{array}$ & $\begin{array}{c}\text { C } \\
\text { (\%) }\end{array}$ & $\begin{array}{c}\text { D } \\
\text { (\%) }\end{array}$ & $\begin{array}{c}\text { Total } \\
\text { (\%) }\end{array}$ & $\begin{array}{c}\text { Positive } \\
\text { Micral (\%) }\end{array}$ \\
\hline$<2$ & 22 & 09 & 04 & 00 & 36 & 13 \\
\hline $2-5$ & 04 & 04 & 04 & 02 & 16 & 10 \\
\hline $5-10$ & 11 & 04 & 11 & 00 & 27 & 15 \\
\hline $10-20$ & 04 & 02 & 04 & 07 & 18 & 13 \\
\hline$>20$ & 00 & 02 & 02 & 00 & 04 & 04 \\
\hline \multicolumn{6}{|c|}{ Table 3. Correlation of MAU with Duration of Diabetes } \\
\hline
\end{tabular}

\begin{tabular}{|c|c|c|c|c|c|c|}
\hline $\begin{array}{c}\text { Serum } \\
\text { Creatinine }\end{array}$ & A (\%) & $\begin{array}{c}\text { B } \\
\mathbf{( \% )}\end{array}$ & $\begin{array}{c}\text { C } \\
\mathbf{( \% )}\end{array}$ & $\begin{array}{c}\text { D } \\
(\mathbf{\%})\end{array}$ & $\begin{array}{c}\text { Total } \\
\mathbf{( \% )}\end{array}$ & $\begin{array}{c}\text { Positive } \\
\text { Micral } \\
\mathbf{( \% )}\end{array}$ \\
\hline $0-1.0$ & 31 & 16 & 13 & 04 & 64 & 33 \\
\hline $1.0-1.5$ & 09 & 02 & 09 & 04 & 24 & 15 \\
\hline $1.5-2.0$ & 02 & 04 & 00 & 00 & 07 & 04 \\
\hline$>2.0$ & 00 & 00 & 04 & 00 & 04 & 04 \\
\hline
\end{tabular}

Table 4. Correlation of MAU with Serum Creatinine Values

\begin{tabular}{|c|c|c|c|c|c|c|}
\hline $\begin{array}{c}\text { Serum } \\
\text { Cholesterol }\end{array}$ & A (\%) & $\begin{array}{c}\text { B } \\
\text { (\%) }\end{array}$ & $\begin{array}{c}\text { C } \\
\text { (\%) }\end{array}$ & $\begin{array}{c}\text { D } \\
\text { (\%) }\end{array}$ & $\begin{array}{c}\text { Total } \\
\text { (\%) }\end{array}$ & $\begin{array}{c}\text { Positive } \\
\text { Micral } \\
\text { (\%) }\end{array}$ \\
\hline$<150$ & 09 & 00 & 00 & 02 & 11 & 02 \\
\hline $150-200$ & 18 & 16 & 11 & 02 & 47 & 29 \\
\hline $200-250$ & 13 & 07 & 11 & 04 & 36 & 22 \\
\hline$>250$ & 02 & 00 & 04 & 02 & 09 & 06 \\
\hline
\end{tabular}

Table 5. Correlation of MAU with Serum Cholesterol Values

\begin{tabular}{|c|c|c|c|c|c|c|}
\hline $\begin{array}{c}\text { Serum } \\
\text { Protein } \\
\text { (g/dL) }\end{array}$ & $\begin{array}{c}\text { A } \\
\mathbf{( \% )}\end{array}$ & $\begin{array}{c}\text { B } \\
\mathbf{( \% )}\end{array}$ & $\begin{array}{c}\text { C } \\
\mathbf{( \% )}\end{array}$ & $\begin{array}{c}\text { D } \\
\mathbf{( \% )}\end{array}$ & $\begin{array}{c}\text { Total } \\
\text { (\%) }\end{array}$ & $\begin{array}{c}\text { Positive } \\
\text { Micral (\%) }\end{array}$ \\
\hline$<5.5$ & 02 & 02 & 02 & 00 & 07 & 04 \\
\hline $5.5-6.0$ & 18 & 07 & 04 & 04 & 33 & 15 \\
\hline $6.0-6.5$ & 09 & 07 & 16 & 02 & 33 & 25 \\
\hline $6.5-7.0$ & 09 & 02 & 00 & 00 & 11 & 02 \\
\hline$>7.0$ & 04 & 04 & 04 & 02 & 16 & 10 \\
\hline \multicolumn{6}{|c|}{ Table 6. Corration MAU with Serum Protein Values } \\
\hline
\end{tabular}

\section{DISCUSSION}

Diabetes mellitus (DM) is probably one of the oldest diseases known to man. It was first reported in Egyptian manuscript about 3000 years ago. ${ }^{8}$ In 1936, the distinction between type 1 and type 2 DM was clearly made. ${ }^{9}$ Type 2 DM was first described as a component of metabolic syndrome in $1988 .{ }^{10}$ Type 2 DM (formerly known as non-insulin dependent DM) is the most common form of DM characterised by hyperglycaemia, insulin resistance, and relative insulin deficiency. ${ }^{11}$ Type 2 DM results from interaction between genetic, environmental and behavioural risk factors. 5,6

Diabetic nephropathy is first recognised as proteinuria. The main reason for performing the test for proteinuria is for the early detection of diabetic nephropathy in a patient who had diabetes for several years. Glomerulus generally prevents large molecules from entering renal filtrate, therefore, protein is not present in the urine when measured by routine Dipstick Quantitative Test. Normally less than $150 \mathrm{mg}$ of proteins per day are excreted in urine. About $1 / 3^{\text {rd }}$ of protein is comprised of urine albumin, $1 / 3^{\text {rd }}$ of small globulins, and $1 / 3^{\text {rd }}$ of Tamm-Horsfall Protein. Most of the proteins are normally reabsorbed by the proximal tubular epithelial cells. Proteinuria is referred to dipstick positive or Albumin Excretion Rate (AER) more than $200 \mu \mathrm{g} / \mathrm{min}$. or $300 \mathrm{mg} / 24$ hrs. ${ }^{8}$

Microalbuminuria is defined as the range in between urinary excretion of albumin of $20-200 \mu \mathrm{g} / \mathrm{min}$. or $30-300$ $\mathrm{mg} / 24$ hours, with a negative dipstick test. The microalbuminuria is also defined as urinary albumin to creatinine ratio. A ratio of greater than $30-300 \mathrm{mg} / \mathrm{g}$ of creatinine is considered as microalbuminuria. ${ }^{9}$

Various epidemiological and cross-sectional studies have reported marked variation in the prevalence of microalbuminuria.10,11 Microalbuminuria has been shown to be an intermediate end point and a powerful predictor of morbidity and mortality in patients with diabetes. In particular, the degree of albuminuria is strongly related both to the progression of diabetic renal disease and to the risk for coronary venous embolism. ${ }^{12}$

Gupta et al reported a prevalence of MAU of $26.6 \%$ in 65 type 2 North Indian non-proteinuric patients, ${ }^{13}$ while John et al reported a prevalence of $19.7 \%$ from a tertiary hospital in Vellore, South India. ${ }^{14}$ Studies in the white UK population 
revealed a prevalence of microalbuminuria of $7 \%-9 \% .13$ The prevalence of microalbuminuria in diabetic 2 patients in the study by Dadhaniya et al was $50 \%$. Varghese et al reported a prevalence of $36.3 \%$ in 1425 type 2 diabetic patients in in Chennai. In the present study conducted amongst 91 diabetic patients, $58.2 \%$ of the patients showed micral positivity.

Earlier studies have reported an increased prevalence of microalbuminuria in men compared with women.15 In another study by Singh et al, the prevalence of microalbuminuria across the genders were not statistically different. ${ }^{16}$ In the present study, to detect the prevalence of microalbuminuria across the genders men are affected more than women. However, no significant statistical correlation is found. ( $\mathrm{p}=0.67)$.

The age of diabetic patients selected for study varied from 15 to 75 years, with peak incidence in the age group 45-55 yrs. No significant correlation was found between age and microalbuminuria as compared to normoalbuminuria $(p=0.07)$. The study is compared with the study of Vishwanath et al. In both the studies, the age group found to be having highest micral positivity is $45-65$ years.

In previous studies, patients with microalbuminuria had higher duration of diabetes compared to normoalbuminuric subjects $(\mathrm{P}<0.001)$. The prevalence of microalbuminuria significantly increased with diabetes duration. ${ }^{14}$ The microalbuminuric patients in several studies had a longer duration of diabetes than the normoalbuminuric group, consistent with findings from referred studies. ${ }^{17}$ Poudel et al found that the Odds Ratio for microalbuminuria became statistically significantly increased only at 16 years after the diagnosis of type 2 diabetes. At this time, $43.7 \%$ of patients had microalbuminuria; this figure remained constant thereafter. ${ }^{18,19}$ However, it is well known that the duration of disease is difficult to establish in type 2 diabetes. In present study, out of $36 \%$ patients with duration of diabetes $<2$ years, approximately one third tested positive for microalbuminuria. As the duration of diabetes advances from 10 years to more than 20 years, number of positive cases rises from $72 \%$ to $100 \%$. The present study shows increasing incidence of MAU after 7 years of diagnosis of diabetes whether IDDM or NIDDM. The incidence decreases after 20 years. Significant statistical correlation is found between microalbuminuria and duration of diabetes $(\mathrm{p}=0.01)$.

On comparing type 1 versus type 2 diabetes, $61 \%$ of the type 2 cases tested positive as against $43 \%$ of the type 1 for MAU, indicating higher prevalence in NIDDM cases. Vijay et al reported a prevalence of $15.7 \%$ in 600 type 2 diabetic patients in Chennai. ${ }^{20}$ Huraib et al reported a prevalence of $16.8 \%$ among 125 type 2 diabetic patients in Saudi Arabia ${ }^{21}$ whereas a previous study in Yazd reported a prevalence of $26.3 \%$ among 650 diabetic patients. ${ }^{22}$ Varghese et al reported a prevalence of $36.3 \%$ in 1425 type 2 diabetic patients in Chennai. ${ }^{23}$

Mean values of FBS $(p=0.91)$ and PPBS $(p=0.14)$ in either of the groups (MAU +/-) is comparable. No significant correlation was found which was compared with studies done by Park et al, Hashim et al. ${ }^{16}$ In other study, the prevalence of microalbuminuria among patients with fasting blood sugar $<140 \mathrm{mg} / \mathrm{dL}$ was $13.9 \%$ and $>140 \mathrm{mg} / \mathrm{dL}$ was $14.4 \%$ respectively. There was no significant correlation between fasting blood sugar and microalbuminuria. ${ }^{22}$ In the present study, $66 \%$ of the tested cases having FBS in the range of $100-150 \mathrm{mg} / \mathrm{dL}$ and PPBS in the range of $200-250$ $\mathrm{mg} / \mathrm{dL}$ shows positive result on Micral strip testing.

In present study, 47 out of 91 patients showed evidence of diabetic retinopathy. Of these 47 patients, $60 \%$ showed positive results for microalbuminuria. The present study is compared with the study of Vishwanath et al which showed comparable results. ${ }^{4} 7 \%$ patients revealed cataract during ophthalmologic examination, of which more than $50 \%$ were positive on Micral testing in our study.

Of the 91 IPD patients evaluated, diabetic foot, tingling numbness and MI were the chief clinical complaints. Amongst them urine of the patients with diabetic foot expressed maximum Micral positivity (84\%). Other less common complaints in the decreasing order of frequency were $\mathrm{CV}$ stroke, Polyuria, Giddiness, Polydipsia, Diminution of vision and burning micturition. Statistically significant association was found between clinical complaints and secretion of microalbumin in urine in our study $(\mathrm{p}=0.01 \%)$.

All the urinary samples with nil or traces of albumin tested positive for microalbuminuria in around $60 \%$ of the samples in both the groups. Association between serum protein and microalbumin is statistically significant $(p=0.01)$.

On comparing the positivity of strip test with serum creatinine, a positive correlation was seen in the rising serum levels of creatinine with the microalbumin excretion in urine. In a study by Farkas et al and Dadhaniya et al, group of patients having serum creatinine more than $1.2 \mathrm{mg} \%$ had maximum percentage $(60.1 \%)$ of patients with microalbuminuria. So significant correlation was found between microalbuminuria and serum creatinine. ${ }^{19,24}$ In present study also significant statistical correlation is found between microalbuminuria and serum creatinine. $(\mathrm{p}=0.01)$.

In one study, the prevalence of microalbuminuria among patients with cholesterol $\leq$ and $>200 \mathrm{mg} / \mathrm{dL}$ was 10.5 and $18.5 \%$ respectively. No statistically significant correlation was found between microalbuminuria and serum cholesterol $(P=0.051) .23$ In other study, as cholesterol level increases, the percentage of patients having microalbuminuria also increases $(49 \%$ with Serum Cholesterol $<220 \mathrm{mg} / \mathrm{dL}$ and $58.57 \%$ with Serum Cholesterol $>220 \mathrm{mg} / \mathrm{dL})^{19}$ which correlated with our study. In present study, Mean Serum Cholesterol value of Micral-positive subjects is $204 \mathrm{mg} / \mathrm{dL}$ as against $186 \mathrm{mg} / \mathrm{dL}$ in Micral-negative cases. ( $\mathrm{p}=0.04)$.

\section{CONCLUSION}

Patients with microalbuminuria should be aggressively targeted for renal and cardiovascular risk factor reduction. According to the American Diabetes Association, type 2 diabetes patients should be screened annually for microalbuminuria. Unfortunately, we are far from routine screening and other recommended goals for these patients in India. In the present study, we investigated the prevalence of microalbuminuria in diabetes patients to emphasise the need for routine screening and better control of risk factors preceding ESRD. More number of studies in large scale population are needed for further verification of MAU as a screening tool to predict ESRD.

\section{REFERENCES}

[1] Prasad KD, Rajaseker P. Study of micro albuminuria as a cardiovascular risk factor in type diabetes mellitus. Iran J Kidney Dis 2012;3(1):12-6. 
[2] Selvin E, Marinopoulos S, Berkenblit G, et al. Metaanalysis: glycosylated hemoglobin and cardiovascular disease in diabetes mellitus. Ann Intern Med 2004;141(6):421-31.

[3] Balam-Ortiz E, Esquivel-Villarreal A, HuertaHernandez D, et al. Hypercontrols in genotypephenotype analysis reveal ancestral haplotypes associated with essential hypertension. Hypertension 2012;59(4):847-53.

[4] Viswanathan M, Snehalatha C, Bhattacharyya PK, et al. Microalbuminuria in NIDDM patients in south India. Indian J Med Res 1991;94:125-9.

[5] Meltzer S, Leiter L, Baneman D, et al. 1998 clinical practice guidelines for the management of diabetes in Canada. DMAJ 1998;159(8 Suppl):S1-29.

[6] Incerti J, Zelmanovitz T, Camargo JL, et al. Evaluation of tests for microalbuminuria screening in patients with diabetes. Nephrol Dial Transplant 2005;20(11):2402-7.

[7] Parving HH, Mogensen CE, Jensen HA, et al. Increased urinary albumin excretion in benign essential hypertension. Lancet 1974;1(7868):1190-2.

[8] Mogensen CE, Chachati A, Christensen CK, et al. Microalbuminuria: an early marker of renal involvement in diabetes. Uremia invest 19851986;9(2):85-95.

[9] Cleveland clinic journal of medicine, Vol: 70, No.3. 2003:255.

[10] Neil A, Hawkins M, Potok M, et al. A prospective population-based study of microalbuminuria as a predictor of mortality in NIDDM. Diabetes Care 1993;16(7):996-1003.

[11] Collins VR, Dowse GK, Finch CF, et al. Prevalence and risk factors for micro and macroalbuminuria in diabetic subjects and entire population of Nauru. Diabetes 1989;38(12):1602-10.

[12] Mogensen CE, Poulsen PL. Microalbuminuria, glycemic control, and blood pressure predicting outcome in diabetes type 1 and type 2. Kidney Int Suppl 2004;92:S40-1.

[13] Gupta DK, Verma LK, Dash SC, et al. The prevalence of microalbuminuria in diabetes: a study from north India. Diabetes Res Clin Pract 1991;12(2):125-8.
[14] Allawi J, Rao PV, Gilbert R, et al. Microalbuminuria in non-insulin-dependent diabetes: its prevalence in Indian compared with European patients. Br Med J 1988;296(6620):462-4.

[15] Singh SP, Parchwani D. Microalbuminuria in diabetic patients: prevalence and putative risk factors. National Journal of Community Medicine 2011;2(1):126-9.

[16] Hashim R, Khalil-ur-Rehman, Ahmed TA, et al. Microalbuminuria and associated risk factors in type 2 diabetes. J Coll Physicians Surg Pak 2004;14(2):84-7.

[17] Retnakaran R, Cull CA, Thorne KI, et al. Risk factors for renal dysfunction in type 2 diabetes: U.K. prospective diabetes study 74. Diabetes 2006;55(6):1832-9.

[18] Pasko N, Toti F, Strakosha A, et al. Prevalence of microalbuminuria and risk factor analysis in type 2 diabetes patients in Albania: the need for accurate and early diagnosis of diabetic nephropathy. Hippokratia 2013;17(4):337-41.

[19] Dadhania BP, Aravat AH, Dhruva GA. Study of microalbuminuria in diabetes type 2 patients as a marker of morbidity (a study of 100 cases in Rajkot city). International Journal of Biomedical and Advance Research 2012;3(10):763-6.

[20] Vijay V, Snehalatha C, Ramachandran A, et al. Prevalence of proteinuria in non-insulin dependent diabetes. J Assoc Physicians India 1994;42(10):792-4.

[21] Huraib S, Abu-Aisha H, Sulimani RA, et al. The pattern of diabetic nephropathy among Saudi patients with noninsulin-dependent diabetes mellitus. Ann Saudi Med 1995;15(2):120-4.

[22] Shekiba M, Afkhami-Ardekani M, Orafa AM. The prevalence of micro and macroalbuminuria in diabetic patients referring to diabetes research center. J Shahid Sadoughi Univ Med Sci Health Services 2003;10:20-4.

[23] Varghese A, Deepa R, Rema M, et al. Prevalence of microalbuminuria in type 2 diabetes mellitus at a diabetes centre in southern India. Postgrad Med J 2001;77(908):399-402.

[24] Farkas K, Noll E, Jermendy G. Screening for microalbuminuria in diabetic patients in the primary health care system. ORVHeti 1996;138(8):459-65. 